\title{
Anticipated Tax Reforms and Temporary Tax Cuts: A General Equilibrium Analysis
}

\author{
Holger Strulik* \\ Timo Trimborn ${ }^{* *}$ \\ Leibniz Universitat Hannover, Discussion Paper No. 406 \\ ISSN 0949-9962
}

Revised Version: February 2010. First Version: August 2008.

\begin{abstract}
Macroeconomic studies of tax policy in dynamic general equilibrium usually assume that reforms hit the economy unexpectedly and last forever. Here, we explore how previous results change when we allow policy changes to be pre-announced and of finite duration and when these facts are anticipated by households and firms. Quantitatively we demonstrate a headstart advantage from pre-announcement that is never caught up by a surprising reform. The welfare gain stemming from a 5-year announcement phase of a corporate tax cut, for example, is estimated to be around 10 percent of the total gain from the reform. We show that impulse responses of important variables like firm value, dividends, and investment differ qualitatively depending on whether the reform comes expected or not. We are also able to demonstrate a genuine welfare gain from temporary tax cuts. Impulse responses generated by our numerical method can be retraced by phase diagram analysis, which facilitates explanation and interpretation of the produced results.

Keywords: tax reform, anticipation effects, investment, economic growth, welfare, corporate finance, capital taxation.
\end{abstract}

JEL: H20, H30, E62, O40 


\section{INTRODUCTION}

While economic research has not yet definitely settled whether and how taxes affect long-term economic growth it is indisputable that the design of the tax law has real effects on the levels of important macroeconomic aggregates such as consumption, investment, income per capita, and welfare. A recent empirical literature has argued that macroeconomic effects of tax policy may be larger than previously thought (e.g. Romer and Romer, 2008, Mountford and Uhlig, 2008) and tax alleviation is high on the policy agenda in many OECD countries. The present article continues the literature that tries to assess the quantitative impact of tax reform on macroeconomic aggregates by calibrating and simulating a dynamic general equilibrium. ${ }^{1}$

Usually this literature assumes that a change of taxes hits the economy unexpectedly and is then expected to last forever. While this might be true in some cases, in reality a tax reform is frequently pre-announced and thus expected quite a while before it actually comes into effect (see the discussion in Alvarez et al., 1998 and Domeij and Klein, 2005). Likewise tax cuts are sometimes temporary. They are announced and thus expected to expire after a certain time. This is, for example, true for the tax relief acts during the Bush administration from 2001 and 2003 of which many measures were announced to end at a certain date between 2007 and 2010 . These observations have motivated the present work, which tries to assess within the dynamic general equilibrium paradigm the macroeconomic consequences of anticipated tax reforms and temporary tax cuts.

Anticipated and/or temporary tax changes are analyzed in a small micro-economic literature on firm investment. ${ }^{2}$ There, dynamics are driven by adjustment costs (and perhaps additionally by different tax treatment of old and new capital). While the micro-research has produced many interesting insights it cannot be used to assess how aggregate macroeconomic performance is affected by tax policy. The partial-equilibrium approach treats wages and interest rates as given and thus neglects important feedbacks through factor price adjustments. Also, since there are no households, the consequences of tax policy on welfare cannot be explored.

Our work shares probably most with two articles by Judd $(1985,1987)$ that investigate anticipated and temporary tax changes within the framework of the neoclassical growth model

\footnotetext{
1 An incomplete list includes Lucas (1990), King and Rebelo (1990), Greenwood and Huffman (1991), Cooley and Hansen (1992), Baxter and King (1993), McGrattan (1994), Stokey and Rebelo (1995), Laitner (1995), Mendoza et al. (1997), Kim (1998), Mendoza and Tesar (1998), Grüner and Heer (2000), Strulik (2003), McGrattan and Prescott (2005).

2 Summers (1981), Abel (1982), Auerbach (1989), Alvarez et al. (1998), and Gourio and Miao (2007).
} 
and which, like the present paper, explain adjustment dynamics by the desire of households to smooth consumption. In fact, our model can be conceptualized as an extension of Judd's work by a corporate sector and a decision problem of firm finance. Within a somewhat simpler institutional framework Judd computes in a quite sophisticated way the savings and welfare effects of tax reform analytically. That way he is able to obtain welfare effects of marginal tax changes.

Yet, tax reforms in reality are non-marginal and in fact sometimes quite drastic. Taking adjustment dynamics properly into account their (non-marginal) quantitative impact on welfare and other aggregates cannot be assessed analytically. Here, we thus propose a new numerical method for their assessment. The method is in detail described in Trimborn et al. (2008) and the general idea of it will be briefly reviewed later in the present paper. The numerical method has a one-to-one correspondence to phase diagram analysis and is thus very intuitive. It nowhere requires a linearization or other approximation of the economic model and allows to obtain impulse responses up to an arbitrarily small, user-specified error.

To our best knowledge our approach is new in the sense that Judd's framwork has so far not been extended towards the quantitative exploration of pre-announced non-marginal tax reforms. The large standard literature on non-optimal taxation within the framework of the neoclassical growth model (e.g. the works cited in footnote 1) focusses on tax shocks, i.e. unexpected changes of fiscal policy.

There exists, however, a small related literature investigating anticipation effects from a different angle and thus pursuing different questions than the present paper. Howitt and Sinn (1989) investigate gradual tax reforms, i.e. fiscal policies for which the tax rate changes continuously and converges towards a final value. Their problem could perhaps best be conceptualized as an un-anticipated tax reform that introduces a whole path of future tax changes, which are then, once the whole reform is known, anticipated.

Furthermore, Domeij and Klein (2005) and Trabandt (2007) explore how results on optimal capital taxation are modified when tax changes are anticipated. That literature generally finds that pre-announcement is detrimental to welfare: the longer the period of pre-announcement the longer is the time that capital holders can prepare by investing less for the optimally high tax that initiates the transition to low or absent tax rates in the long-run. In our framework of exogenous, non-optimal tax reform, preannouncement allows households and firms to prepare for a unique tax change at some future date (for example, by investing more already today in 
order to prepare for a future reduction of the corporate tax rate). Consequently, we generally find a positive welfare effect from pre-announcement. ${ }^{3}$

Because we can retrace impulse responses to tax changes with phase diagrams, our results are much richer than "only" an exploration of welfare gains. In particular, we explain how real variables (e.g. investment and growth) and financial variables (e.g. dividend policy and firm leverage) change during the announcement phase and after actual implementation of a policy. This allows us to explain why and how macroeconomic aggregates react differently depending on whether a tax reform is anticipated or unexpected. We employ the combination of numerical method and phase diagram analysis also to explore how permanent and temporary tax cuts affect macro-economic behavior differently.

The concrete framework that we use for our investigation consists of a neoclassical growth model with explicit consideration of a corporate sector and a firm finance decision. For our purpose this setup combines several advantages. It allows for the introduction of a rich set of tax parameters and a discussion of real and financial impacts of tax reform and it is still simple enough to be reduced to a two-dimensional dynamic system such that we can exploit phase diagram analysis to provide economic intuition for the results. ${ }^{4}$

The next section describes the model and the implementation of anticipation effects. Section 3 investigates anticipated enactment and termination of tax reforms qualitatively. Section 4 explains how our numerical method exploits the principles derived from phase diagram analysis, Section 5 presents our results, the quantitative impact of anticipation on adjustment dynamics on several macroeconomic aggregates and on welfare. Section 6 concludes.

\section{The Model}

2.1. Firms. We consider a continuous time, infinite horizon model of a representative corporation maximizing present value of the firm (as in Sinn, 1987, Auerbach, 2001) augmented by costly debt (as in Strulik, 2003). Let $V$ denote the value of the firm, $S$ the flow of funds from the

\footnotetext{
3 In order to avoid confusion, it may be helpful to emphasize that we compare the cases of having a tax change at a certain date pre-announced or not. Of course, implementing a generally beneficial reform earlier will always be better.

4 Tax policy in this framework has been investigated by Turnovsky (1982, 1990), Sinn (1987), Osterberg (1989), and Strulik (2003). None of the earlier literature has been concerned with pre-announced and temporary tax policy.
} 
issue of new shares, and $D$ dividends. Following the standard literature (the "new view", Auerbach 2001) we focus on both $D$ and $S$ being non-negative, i.e. we exclude share repurchases. ${ }^{5}$ Let furthermore $r$ denote the gross interest rate on bonds, $\tau_{d}$ the tax rate on dividends, $\tau_{p}$ the tax rate on private interest income and $\tau_{c}$ the tax rate on capital gains. All variables are generally functions of time but for notational convenience we omit a time index unless necessary for understanding. Tax rates are treated parameterically since they change either only occasionally (at discrete events) or not at all.

No-arbitrage at capital market equilibrium requires that the after-tax return of bonds equals the return obtained from investment in shares consisting of after tax earnings from capital gains and dividends.

$$
\left(1-\tau_{p}\right) r V=\left(1-\tau_{c}\right)(\dot{V}-S)+\left(1-\tau_{d}\right) D
$$

Integrating equation (1) and applying the terminal condition that discounted firm value converges to zero yields present value of the firm.

$$
V(t)=\int_{t}^{\infty}\left(\frac{1-\tau_{d}}{1-\tau_{c}} D-S\right) e^{-\int_{t}^{v} \frac{1-\tau_{p}}{1-\tau_{c}} r(s) d s} d v
$$

The implementation of tax depreciation follows Sinn (1987). A proportion $z$ of a unit of investment can be deducted immediately and the remainder is tax-deductible over time with the rate of economic depreciation $(\delta)$. Additionally to preferential tax treatment of depreciation other subsidies may directly reduce the cost of investment. In order to be brief we subsume all investment specific allowances in $z$ as investment tax credit. Let $T_{r}$ denote the tax on corporate income at rate $\tau_{r}, \Pi$ accounting profits, $I$ net investment and $\dot{B}$ new debt. Gross dividends are then defined by

$$
D=\Pi+\dot{B}+S-I\left(1-z \tau_{r}\right)-T_{r} .
$$

Firms face an exogenously growing level of technology $A$ and produce with constant returns to scale with respect to capital $K$ and labor in efficiency units $A L$. The production function $F$ has positive and decreasing marginal returns. Each unit of labor receives a wage $w$. Firms face unit costs of debt consisting of the market interest rate and a further cost depending on the debt ratio $(B / K)$, which may best be thought of as agency costs of debt. Both costs are tax

\footnotetext{
5 Our results nowhere hinge on this assumption, we make it only in order to avoid distracting case differentiation.
} 
deductible. Because the corresponding cost function $a(B / K)$ is not explicitly micro-founded, we merely require that its curvature ensures an interior solution of the maximization problem. ${ }^{6}$

Accounting profits are given by $\Pi=F(K, A L)-w L-\delta K-r B-a(B / K) B-\tau_{r} z I$ and the corporate tax is given by $T_{r}=\tau_{r} \Pi$. Inserting these expressions into (3) we get gross dividends $(4)$.

$$
D=\left(1-\tau_{r}\right)\left[F(K, A L)-w L-\delta K-r B-a(B / K) B-\tau_{r} z I+\frac{\dot{B}+S-\left(1-\tau_{r} z\right) I}{1-\tau_{r}}\right] .
$$

The corporation's part of the model is completed by the law of motion for capital (5).

$$
I=\dot{K}
$$

The Hamiltonian for maximization of (2) subject to (4)-(5) and $D \geq 0$ and $S \geq 0$ is:

$$
\begin{aligned}
\mathcal{H}= & \left(1-\tau_{r}\right)\left(\mu_{D}+\frac{1-\tau_{d}}{1-\tau_{c}}\right) \times \\
& \left\{F(K, A L)-w L-\delta K-r B-a(B / K) B-\tau_{r} z I+\left(\dot{B}+S-\left(1-\tau_{r} z\right) I\right) /\left(1-\tau_{r}\right)\right\} \\
& -S+q_{K} I+q_{B} \dot{B}+\mu_{S} S
\end{aligned}
$$

where $q_{K}$ and $q_{B}$ denote the costate variables associated with capital and debt and $\mu_{D}$ and $\mu_{S}$ are the slack variables associated with dividends and share issue. Let capital per labor in efficiency units be defined as $k:=K /(A L)$, the debt ratio as $b:=B / K$, and production per effective labor as $f(k):=F(k, 1), f^{\prime}(k)>0, f^{\prime \prime}(k)<0$. The first order conditions for an optimal choice of investment $(I)$ and employment $(L)$, share issue $(S)$ and new debt $(\dot{B})$ are summarized in (6).

$$
\begin{aligned}
& w=A\left[f(k)-f^{\prime}(k) k\right] \\
& 1-\frac{1-\tau_{d}}{1-\tau_{c}}=\mu_{D}+\mu_{S} \\
& \left(\mu_{D}+\frac{1-\tau_{d}}{1-\tau_{c}}\right)\left(1-\tau_{r}^{2} z\right)=q_{K} \\
& \frac{1-\tau_{d}}{1-\tau_{c}}=q_{B}+\mu_{D} \\
& \left(1-\tau_{r}\right)\left(\mu_{D}+\frac{1-\tau_{d}}{1-\tau_{c}}\right)\left[f^{\prime}(k)-\delta+a^{\prime}(b) b^{2}\right]=q_{K} r \frac{1-\tau_{p}}{1-\tau_{c}}-\dot{q}_{K}
\end{aligned}
$$

\footnotetext{
6 A micro-foundation of agency costs could be integrated into the model at the expense of further formal complication and notational clutter, see Strulik (2008).
} 


$$
-\left(1-\tau_{r}\right)\left(\mu_{D}+\frac{1-\tau_{d}}{1-\tau_{c}}\right)\left[r+a(b)+a^{\prime}(b) b\right]=q_{B} r \frac{1-\tau_{p}}{1-\tau_{c}}-\dot{q}_{B}
$$

We assume (and confirm numerically below) that our representative firm distributes regular dividends, i.e. $D>0$, such that the complementary slackness condition, $\mu_{D} D=0$ requires $\mu_{D}=0$. According to the US tax system $\tau_{d}>\tau_{c}$. This implies that according to (6b) $\mu_{S}>0$ such that $S=0$, implying that firms issue (regularly) no new shares and retained profits are the preferred method of accumulating equity capital. This, however, does not imply that firms will never issue new shares. If tax rates faced by the corporate sector change, firms may want to adjust their equity capital instantaneously. But since output and profits are flows, retained earnings cannot jump so that firms have to rely on $S>0$ in order to increase their equity instantaneously. This way, the "new view" is compatible with the empirical observation of occasional issues of new shares.

According to (6c), marginal costs of investment from shareholders' perspective equal marginal value of investment (measured by $q_{K}$ ). Condition $(6 \mathrm{~d})$ requires that the marginal value of new debt equals its marginal costs: substituting one Dollar of retained earnings by new debt increases dividends by $\left(1-\tau_{d}\right) /\left(1-\tau_{c}\right)$. The left hand side of $(6 \mathrm{e})$ gives net marginal returns on capital allocated within the firm from shareholders' perspective. It equals net marginal returns on capital outside the firm (net interest payments plus depreciation of value). Note that an additional unit of capital does not only increase output by $f^{\prime}(k)-\delta$ but also has an additional positive effect by lowering the debt ratio. The left hand side of (6f) gives marginal costs of debt within the firm consisting of interest costs plus marginal leverage costs, which equal the marginal returns on debt outside the firm (net returns on bonds plus depreciation of value).

The necessary conditions are sufficient and an interior solution is - if it exists - unique, if the non-maximized Hamiltonian is strictly concave in states and controls. With respect to capital and debt strict concavity of the Hamiltonian requires that total costs of leverage, $a(B / K) B$, are strictly convex in $K$ and $B$, implying:

$$
2 a^{\prime}(b)+a^{\prime \prime}(b) b>0
$$


which is assumed to hold henceforth. Finally, we assume that the tax burden is higher when investment is financed by equity than when it is financed by debt:

$$
\left(1-\tau_{p}\right)>\left(1-\tau_{c}\right)\left(1-\tau_{r}\right)
$$

The assumption ensures that firms are always realizing an interior solution for financial structure, i.e. that they are never completely equity financed. A tax advantage of debt finance is empirically supported for the US and many other OECD countries (OECD,1991, Graham, 2000, 2006).

From the first order conditions (6) we derive the optimal debt ratio as an implicit function of the capital labor ratio and the tax law.

$$
0=f^{\prime}(k)-\delta+a^{\prime}(b) b^{2}-\left[\frac{\left(1-\tau_{r}^{2} z\right)\left(1-\tau_{p}\right)}{\left(1-\tau_{p}\right)-\left(1-\tau_{c}\right)\left(1-\tau_{r}\right)}\right]\left(a(b)+a^{\prime}(b) b\right) .
$$

2.2. Households. Households maximize intertemporal utility from consumption $C$ according to

$$
\max \int_{0}^{\infty} \frac{C^{1-\sigma}}{1-\sigma} e^{-\rho t} d t
$$

where $\rho$ is the time preference rate and $1 / \sigma$ the intertemporal elasticity of substitution. Households supply one unit of labor, receive a wage $w_{t}$, pay a tax on wage income at rate $\tau_{w}$, and receive lump-sum government transfers, $T$. Their financial wealth, $W$, consists of equity holdings, $V$, and bond holdings, $B$, and their budget constraint is given by

$$
\dot{B}=\left(1-\tau_{w}\right) w+\left(1-\tau_{p}\right) r B+\tau_{d} D+T-S-\tau_{c}(\dot{V}-S)-C
$$

After inserting $\dot{B}$ and $\dot{V}$ from (1) into $\dot{W}=\dot{V}+\dot{B}^{H}$ the budget constraint reads

$$
\dot{W}=\left(1-\tau_{w}\right) w+\left(1-\tau_{p}\right) r W+T-C
$$

The first-order conditions for maximizing (10) given (11) provide the Ramsey rule

$$
\frac{\dot{C}}{C}=\frac{\left(1-\tau_{p}\right) r-\rho}{\sigma} .
$$

2.3. Capital market equilibrium. Generally, a capital market equilibrium requires $W=$ $V+B$. The interesting case here occurs at those occasional events when a tax reform triggers a restructuring of firm capital. These instantaneous movements of financial funds change debt and equity holdings of firms and thus the value of firms but they cannot change aggregate 
wealth $W$ if the tax change was pre-announced and thus expected. Aggregate wealth is a stock variable that cannot jump at the moment of an unexpected event. Intuitively, an expected jump of wealth would indicate arbitrage opportunities. These, however, are ruled out by the no-arbitrage condition. Thus at the point of time of financial restructuring, denoted by $\tilde{t}$,

$$
\Delta B(\tilde{t})=\Delta V(\tilde{t})
$$

However, if we allow for a discrete financial restructuring at $\tilde{t}$, firms may issue a mass of new shares at $\tilde{t}$ or pay exceptional dividends at $\tilde{t}$. We denote this change by $S(\tilde{t})$ and $D(\tilde{t})$, respectively, and consider it for firm value by applying the Dirac delta function. ${ }^{7}$ Accordingly, firm value modifies to

$$
V(t)=\int_{t}^{\infty}\left(\frac{\theta\left(D+\delta_{\tilde{t}}(v) D\right)}{1-\tau_{c}}-\left(S+\delta_{\tilde{t}}(v) S\right)\right) e^{-\int_{t}^{v} \frac{1-\tau_{p}}{1-\tau_{c}} r(s) d s} d v
$$

But by how much does firm value change? To answer that question we calculate firm value over a small interval $[\tilde{t}, \tilde{t}+\Delta t]$ according to equation (14).

$$
\begin{aligned}
V(\tilde{t}+\Delta t) e^{-\int_{\tilde{t}}^{\tilde{t}+\Delta t} \frac{1-\tau_{p}}{1-\tau_{c}} r(s) d s}-V(\tilde{t}) & = \\
& \int_{\tilde{t}}^{\tilde{t}+\Delta t}-\frac{\theta\left(D(s)+\delta_{\tilde{t}}(s) D(s)\right)}{1-\tau_{c}} e^{-\int_{\tilde{t}}^{s} \frac{1-\tau_{p}}{1-\tau_{c}} r(u) d u} d s \\
+ & \int_{\tilde{t}}^{\tilde{t}+\Delta t}\left(S(s)+\delta_{\tilde{t}}(s) S(s)\right) e^{-\int_{\tilde{t}}^{s} \frac{1-\tau_{p}}{1-\tau_{c}} r(u) d u} d s .
\end{aligned}
$$

Consider first instantaneous restructuring through issues of new shares $S$. For $\Delta t \rightarrow 0$ the first integral at the right hand side converges to zero since $D$ remains to be a flow and $D(\tilde{t})=0$. With contrast, $S$ has a discrete mass at point $\tilde{t}$ so that the second integral at the right hand side converges to $S(\tilde{t})$. Likewise, if there is restructuring through dividends, the second integral converges to zero for $\Delta t \rightarrow 0$ whereas $D$ has positive mass and the first integral converges towards $-\theta D(\tilde{t}) /\left(1-\tau_{c}\right)$. Summarizing we have

$$
\Delta V(\tilde{t})= \begin{cases}S(\tilde{t}) & \text { if } \Delta V(\tilde{t})>0 \\ -\frac{\theta}{1-\tau_{c}} D(\tilde{t}) & \text { if } \Delta V(\tilde{t})<0 .\end{cases}
$$

7 We denote the Dirac delta function by the symbol $\delta$. The function is defined by $\delta_{\tilde{t}}(t)=\left\{\begin{array}{ll}+\infty, & t=\tilde{t} \\ 0, & t \neq \tilde{t}\end{array}\right.$ and $\int_{-\infty}^{\infty} \delta_{\tilde{t}}(t) d t=1$, see Li and Wong (2008) and the citations therein. 
Equations (13) and (15) describe the general equilibrium effects of financial restructuring and its consequence on firm value. In words, if firms restructure by paying exceptional dividends, households reinvest income by buying additional bonds. If firms issue new shares, households adjust by selling bonds.

2.4. Government and General Equilibrium. Government revenues are completely paid out to households in form of either transfers or interest payments on government bonds. Using Ricardian equivalence, the path of government debt necessary to balance the current budget is represented by a time series of lump sum income transfers. ${ }^{8}$

The economy consists of a continuum of households and a continuum of firms both of measure one. GDP is used for private consumption, investment and agency costs

$$
Y=C+I+\delta K+a(b) B=F(K, A L) .
$$

Inserting this into (5) and dividing by $K$ we obtain growth of aggregate capital as:

$$
\dot{K} / K=[f(k) / k-a(b) b]-C / K-\delta
$$

Next, we introduce the consumption-capital ratio $c=C / K$ and assume that technology grows at constant rate $\gamma$. Using (12) and (16), the economy is represented as the following system in $k$ and $c$.

$$
\begin{aligned}
\dot{k} / k & =f(k) / k-a[b(k)] b(k)-c-\delta-\gamma \\
\dot{c} / c & =\left[\left(1-\tau_{p}\right) r(k)-\rho\right] / \sigma-(\gamma+\dot{k} / k) .
\end{aligned}
$$

The main deviation from the standard neoclassical growth model is that the interest rate is not explicitly given by capital productivity but "only" implicitly determined on the financial market. To see this clearly, derive from (9) financial structure $b$ as an implicit function of firm size $k$. Then conclude from (6d) and (6f) $r+a(b)+a^{\prime}(b)=r\left(1-\tau_{p}\right) /\left[\left(1-\tau_{c}\right)\left(1-\tau_{r}\right)\right]$, which expresses the interest rate implicitly as a function of firm leverage. It can be shown

\footnotetext{
8 The assumption that tax revenue is repaid lump sum to households allows us to identify and explain with help of phase diagram analysis the consequences of a particular tax change on macro-aggregates and, in particular, the consequences of having the tax change pre-announced. We would loose this feature if we would instead assume that the government budget is balanced by equilibrating the revenue lost from reducing one distortionary tax by raising another distortionary tax. Our numerical method is, of course, suitable for the analysis of pre-announced and/or temporary changes of several tax rates simultaneously.
} 
that leverage and interest rates are positively correlated $(\mathrm{d} r / \mathrm{d} b>0)$ and that larger firms are relatively less indebted $(\mathrm{d} b / \mathrm{d} k<0)$. This provides, as for the standard neoclassical growth model, a negative correlation between capital stock and returns $\mathrm{d} r / \mathrm{d} k<0$ and ensures a unique and saddlepoint-stable equilibrium (See Strulik, 2003, for a proof of these claims).

Given the saddlepoint property, obtaining adjustment dynamics after a permanent, nonanticipated tax reform is straightforward. At the time of the tax change, the state variable $k$ cannot jump and consumption jumps on the stable manifold along which the economy travels towards the new steady-state, determined by the after-reform tax law. Generally, growth and welfare effects of these kinds of tax changes have been investigated in many articles and in particular, for the current model in Strulik (2003). If the tax change is anticipated and/or known to be non-permanent, however, assessing adjustment dynamics is somewhat more involved.

\section{Anticipated Tax Policy: Qualitative Analysis}

In the real world, people may know both the point in time when a tax policy comes into effect and the point in time when it terminates - if it terminates. For better understanding, however, it is useful to investigate the effects that arise from pre-announcement and from known expiry separately. Linguistically, we may distinguish an anticipated tax reform, i.e. a policy that is regarded to be permanent and which will become operative in the future at a certain preannounced date (like, for example, elements of Germany's "Agenda 2010") from a temporary tax cut, which is enacted more or less spontaneously and known to be terminated at a certain date in the future (like many elements of the 2001 and 2003 tax relief acts of the Bush administration). ${ }^{9}$

3.1. Anticipated Tax Reform. Consider, as an illustration, an anticipated and permanent cut of the corporate tax rate which is announced at time $t_{0}$ and which becomes effective at a future date $\tilde{t}>t_{0}$. At time $t_{0}$ the economy is assumed to rest at the pre-reform steadystate. Because firms and households know in advance that the reform will happen, they use the opportunity to adjust their behavior already from time $t_{0}$ onwards.

Adjustment dynamics can be conveniently analyzed in a phase diagram. In Figure 1 the panel on the left introduces the pre- and after reform equilibria and general movements within the phase diagram. The panel on the right shows adjustment dynamics of the specific reform.

\footnotetext{
9 We ignore elements of uncertainty stemming, for example, from commitment problems or (unexpected) change of the incumbent party. For a related paper on policy uncertainty, see Alvarez et al. (1998).
} 
Initially the economy is situated at $\left(k_{\text {old }}^{*}, c_{\text {old }}^{*}\right)$. Grey curves show the initial isoclines and grey arrows indicate the direction of motion of trajectories around the steady-state. A cut of the corporate tax rate $\tau_{r}$ increases the incentive to take up more debt in order to finance additional investment. Thus at the after-reform steady-state both $k^{*}$ and $b\left(k^{*}\right)$ will be higher. The $\dot{c}=0$ curve moves to the right because of higher capital accumulation (lower marginal return on capital) and the $\dot{k}=0$-curve shifts downward because of higher agency costs of debt. Black lines indicate the new isoclines and the black vector field indicates the direction of movement of trajectories associated with the new equilibrium. ${ }^{10}$

\section{Figure 1: Pre-announced Tax Reform: Phase Diagram}
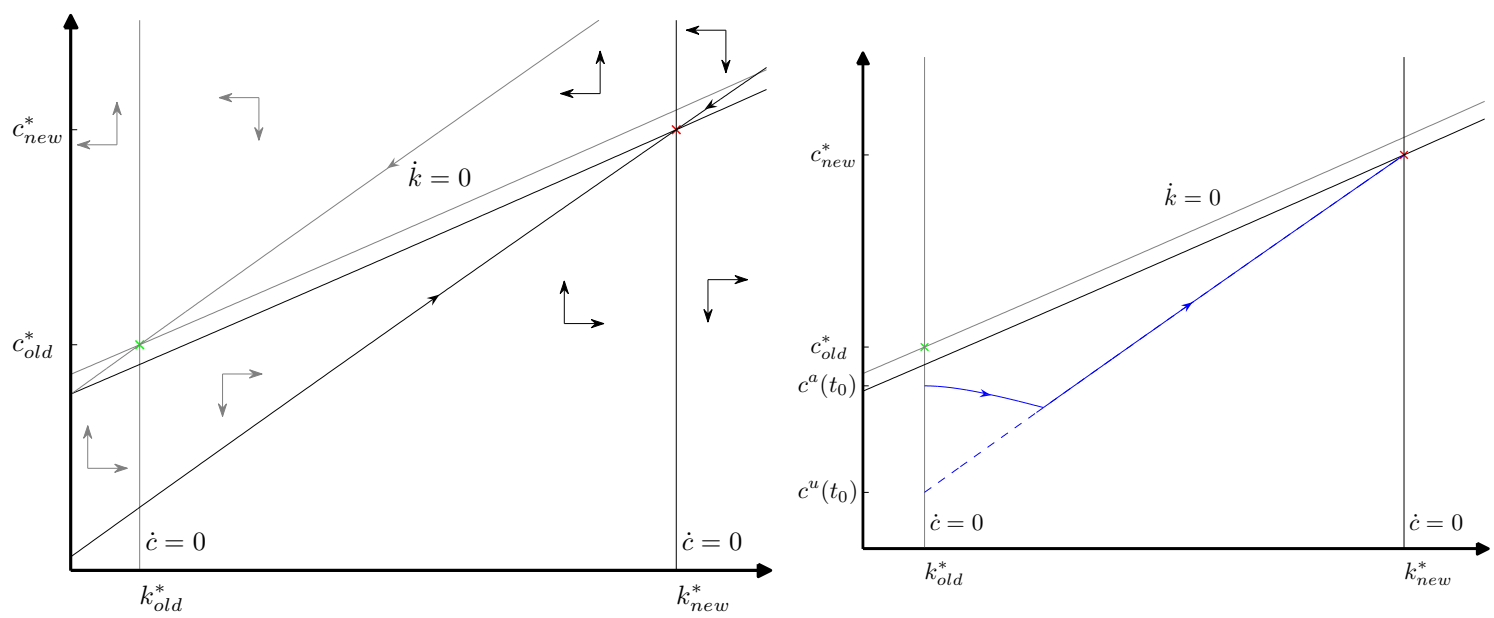

The basic intuition for the understanding of adjustment dynamics is that there can only be a jump of household wealth and thus of consumption at the moment of an unexpected event. As explained above, the assumption of no-arbitrage rules out jumps if everything is expected and thus correctly anticipated by households and firms. If agents would not expect the tax reform, the economy would rest at the initial steady-state from $t_{0}$ to $\tilde{t}$. At $\tilde{t}$ households and firms would rearrange their decision plans such that the economy would immediately jump on the stable manifold associated with the after-reform steady-state, represented by a dashed line on the right panel of Figure 1. This behavior follows stringently from the logic of the first order conditions and the transversality condition requiring that the economy converges towards the steady-state. Because there cannot be any further jumps, and because any trajectory not

\footnotetext{
10 Theoretical analysis identifies a higher capital stock at the new equilibrium but leaves the change of steadystate consumption indeterminate. In line with our numerical results below Figure 1 assumes that the shift caused by interest rates (i.e. through the savings channel) is more pronounced than the shift caused by agency costs of debt (through the credit channel) such that consumption is actually higher at the new equilibrium.
} 
starting on the stable manifold will never arrive at the steady-state, the economy has to be on the manifold at $\tilde{t}$.

When households and firms anticipate the tax reform they choose already a different pattern of investment and consumption during the time between first knowledge and coming into effect of the policy, i.e. during $\left[t_{0}, \tilde{t}\right]$. At time $\tilde{t}$, there is no new information so that households' wealth evolves continuously. Hence, the shadow price of wealth and consumption evolves continuously as well. For this to be the case, households choose an initial value of consumption $c^{a}\left(t_{0}\right)$, such that the resulting trajectory implied by the vector field meets the stable manifold at $\tilde{t}$. This path is represented in the panel on the right hand side of Figure 1 by a solid line.

In order to understand the movement of transitional dynamics, note that until $\tilde{t}$ the grey vector field associated with the pre-reform steady-state applies whereas the black vector field associated with the after-reform steady-state applies from $\tilde{t}$ onwards. A higher level of consumption compared with the old steady-state level at $\tilde{t}$ would result in a trajectory leading in north-westward direction. This trajectory would radiate from the new stable manifold and, hence, could not meet it at time $\tilde{t}$. Therefore, consumption has to jump down at $t_{0}$.

This downward shift of consumption means that the announcement of the tax cut already spurs investment before the reform actually comes into force. We can also conclude that the downward jump of consumption has to be smaller than for an unanticipated reform. Trajectories starting with $c<c_{\text {old }}^{*}$ under the old tax regime point to the south-east. Hence, any $c^{a}\left(t_{0}\right)$ lower than $c^{u}\left(t_{0}\right)$ would result in a trajectory leading away from the new stable manifold. The economy would never arrive at the after-reform steady-state.

Financial structure of firms, with contrast, does not change discontinuously at the time when the reform is announced, i.e. at time $t_{0}$. For given macroeconomic aggregates and constant policy the structure of finance depends solely on current taxes and the stock of capital. Implicitly differentiating (9) we find $\partial b / \partial \tau_{r}>0$. Thus, financial structure of firms changes discontinuously in favor of equity when the reform becomes operative, i.e. at time $\tilde{t}$. Because of no-arbitrage this financial restructuring must not affect aggregate wealth (and consumption) of households. Qualitatively, we know from equations (13) and (15) that firms issue new shares at $\tilde{t}$ such that expenditure by households $(S)$ equals the gain in aggregate firm value $(\Delta V)$. The quantitative impact, however, that an anticipated tax reform has on financial structure, capital accumulation, consumption, and welfare, is unknown. It will be investigated in Section 5 . 
3.2. Non-permanent Tax Policies. Consider now the opposite case and suppose that a tax law becomes known at the moment when it becomes effective (for example, because it is known that a proposal once it has passed legislature will be retroactively applied) and that the law changes the tax rate only for a finite period of time, which is known by the economic agents. Afterwards, the original policy applies again. Typical examples are many traditional Keynesian policies, like temporary investment tax credits and accelerated depreciation rules. As an illustration we thus consider a non-anticipated increase of $z$ which is known to last for $\tilde{t}$ time periods.

Figure 2: Temporary Rise of Investment Tax Credit: Phase Diagram
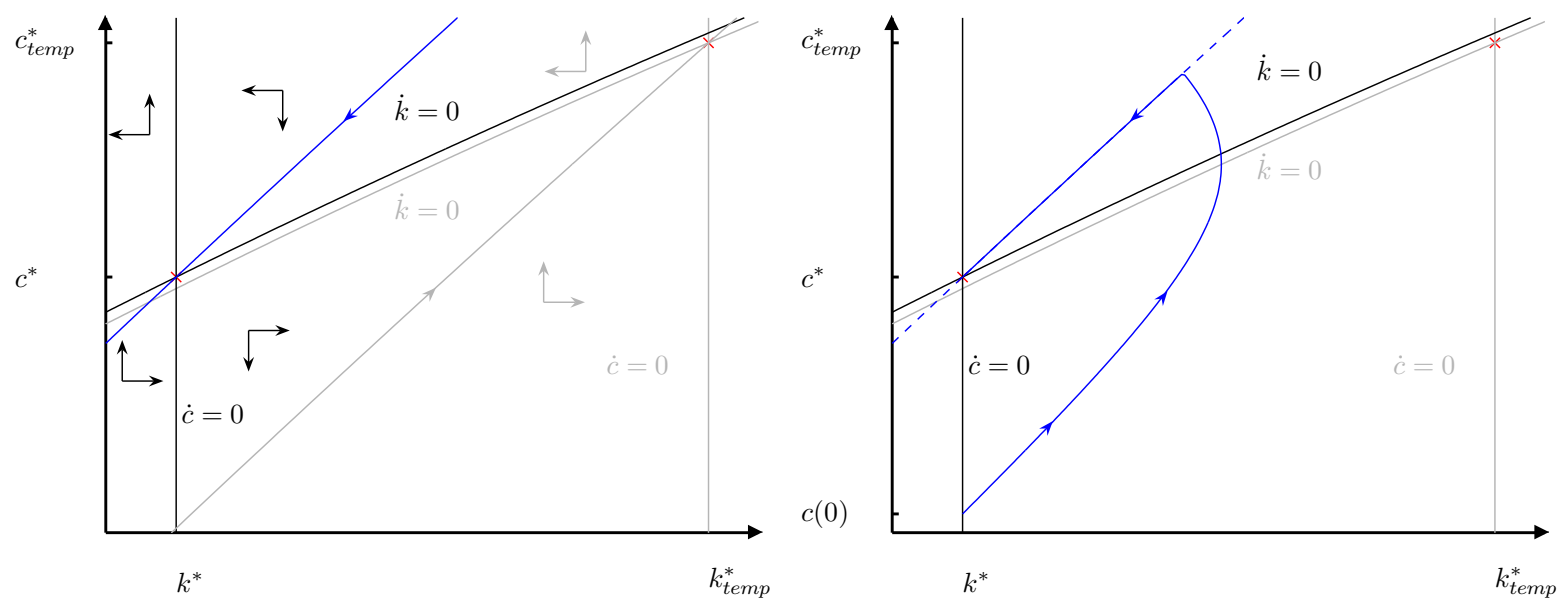

An increase of the investment tax credit $z$ makes investment more attractive and leads to higher capital accumulation and lower interest rates. It shifts the $\dot{c}=0$-curve to the right. The $\dot{k}=0$-curve shifts down a little because $b\left(k^{*}\right)$ and the entailed agency costs of debt are higher at the new steady-state. However, the policy change is known to be only temporary. In Figure 2 black isoclines and vector fields are associated with the initial equilibrium, which is also the terminal equilibrium. Grey isoclines and vector fields are associated with the equilibrium towards which the economy temporarily converges $\left(k_{t e m p}^{*}, c_{t e m p}^{*}\right)$. General dynamics are introduced in the panel on the left. Dynamics of the specific policy are shown in the right panel.

For the construction of adjustment dynamics note that at the time when the temporary tax credit becomes effective the grey vector field applies while at the time when the policy expires the economy must have reached the stable manifold leading to the old (i.e. the permanent) steady-state. This behavior follows the same logic as explained above. Economic agents receive 
no new information at the time when the policy expires because the expiry date is already known in advance. Consequently, no-arbitrage rules out a jump of aggregate wealth implying that the associated shadow price of wealth and consumption cannot jump as well.

Because the policy is temporarily expansive, adjustment along the stable manifold has to be from above as indicated in the panel on the right of Figure 2. In order to reach the manifold along a path that obeys the grey vector field, the initial jump of consumption must be in direction of lower $c$. The policy implies a steep spontaneous increase of investment with subsequently falling investment rates. Note that the inherent logic of adjustment dynamics also implies that the trajectory describing the optimal consumption strategy crosses the $\dot{k}=0$ isocline from below before it reaches the manifold. Otherwise, the economy would never return to the initial steady-state. The model thus predicts that investment falls below its initial level at a time when the favorable investment credit is still effective. Finally, observe that consumption reaches its highest level at the moment when the temporary policy is terminated.

Generally, phase diagrams of anticipated reforms have already been analyzed elsewhere (Summers, 1981, Abel, 1982, Judd, 1985). We have been reviewing these principles in such a detailed manner because we are exploiting them with our numerical solution technique, the application of which to anticipated tax reform and temporary tax relief is the major innovation of the present paper.

\section{Method and Calibration}

4.1. Method. For calculating adjustment dynamics we apply the relaxation algorithm (Trimborn et al., 2008). The principle of relaxation is to construct a large set of non-linear equations, the solution of which represents the desired trajectory. This is achieved by a discretization of the involved differential equations on a mesh of points in time. The set of differential equations is augmented by algebraic equations representing equilibrium conditions or (static) no-arbitrage conditions at each mesh point. Finally, equations representing the initial and final boundary conditions are appended. The whole set of equations is solved simultaneously.

The special property of our optimization problem is that the size of the jumps fulfilling (13) and (15) follows from the continuity of capital $(k)$, wealth $(W)$, consumption $(C)$ and the respective shadow prices. A jump in financial structure is thus optimal according to (13) and (15) 
if it is accompanied by a continuous movement of consumption, capital, and wealth. The relaxation algorithm is demanding just this property by treating differential and algebraic variables conceptually differently. For differential variables there are differential equations present (e.g. for $k$ ) whereas this is not the case for algebraic variables (e.g. for $b$ ). The distinction is important because it implies that differential variables are connected along time through difference equations whereas no such connection exists for algebraic variables. This feature allows algebraic variables to jump whereas differential variables have to be continuous (potentially with corners). Thus, while the algorithm forces $W$ to evolve continuously, its components $V$ and $B$ can exhibit interior jumps of the same magnitude, but with opposite signs. This way the algorithm reveals the extraordinary payout of dividends (or the extraordinary issue of shares) at the time when a policy comes into effect and firms adjust financial structure. ${ }^{11}$

4.2. Calibration. We calibrate the model with U.S. data. We use a Cobb-Douglas production function and set the capital share $\alpha$ to $1 / 3$. Instead of imposing a linear or quadratic form for the unit costs of debt, we try to find parameters of the isoelastic function $a(b)=a_{0} b^{a_{1}}$ such that the simulated behavior of the representative firm generates the correlation between taxation and leverage estimated for the average U.S. firm by Gordon and Lee $(2001,2007)$. We set $\tau_{r}=0.35$ according to the marginal tax rate applying for U.S. corporations at the highest tax bracket. For tax rates on private capital income we calibrate the initial steady-state such that it reflects the U.S. tax law before the (mostly temporary) tax cuts of the Bush administration. Following Gourio and Miao (2010) we set $\tau_{p}=0.25, \tau_{d}=0.25, \tau_{r}=0.35$ and a statutory capital gains tax of 0.20. The tax on capital gains is an effective rate and following Poterba (2004) we set $t_{c}=0.2 / 4$. Finally we set $\tau_{w}$ to the value of 0.36 , which has been estimated by Carey and Tchilinguirian (2000) as the average effective tax rate on labor income, and - following the approach in Sinn (1987, pp. 57-60) $-z=0.4$. From various other calibration studies we adopt $\rho=0.02$ and $\gamma=0.015$.

The remaining parameters are determined in the following way. Eqs. (9), and (17) evaluated at the steady state are required to yield $b^{*}=0.194$ (the average debt ratio according to Gordon and Lee), a long-run capital output ratio of $k^{* 1-\alpha}=2.16$, and a long-run gross investment ratio of $(I+\delta K) / K \cdot(K / Y)=(\delta+\gamma) k^{* 1-\alpha}=0.17$ (both values according to Mendoza and

\footnotetext{
11 A detailed description of the numerical method is available at: http://kaldor.vwl.uni-hannover.de/timo/. The MATLAB code is available upon request.
} 
Tesar, 1998). This implies a net investment ratio $I / K$ of 3.24 and determines $\delta=0.064$ and $\sigma=2.6$. Finally, the parameters of the debt cost function are determined by requiring $a(b)=0$ for $b=0$ and that our benchmark economy reproduces Gordon and Lee's (2001) estimate that a five percentage point increase in $\tau_{r}$ raises the debt ratio by about 1.8 percentage points. This provides the estimates $a_{0}=6.6$ and $a_{1}=4.7 .^{12}$

\section{Anticipated and Temporary Tax Policy: Quantitative Analysis}

5.1. Pre-Announced Corporate Tax Reform. Many OECD countries have recently enacted quite drastic cuts of corporate taxes or are planning them for the future. Corporate tax reforms are frequently known several years in advance (Alvarez et al, 1998, Domeij and Klein, 2005). In line with these observations we assume a tax cut of $\tau_{r}$ of 10 percentage points and start our investigation at year 0 , from which onwards it is known that in year 5 there will be a corporate tax reform.

In Figure 3 we show the consequences for major economic variables: capital stock $(k)$, consumption $(c)$, aggregate wealth $(W)$, debt ratio $(b)$, firm value $(V)$, net investment rate $I / Y$, dividends per share $(D / V)$, tax revenue, and economic growth of per capita output $\left(g_{y}\right)$. Values for macroeconomic aggregates are detrended and expressed relative to their pre-reform steadystate values. Values for economic rates (i.e. $b, I / Y$, and $g_{y}$ ) are expressed in percentage points. In each panel the after-reform steady-state value to which the economy eventually converges is indicated by a circle. Solid lines show adjustment dynamics for the pre-announced reform. For comparison, dashed lines show adjustment dynamics when the same reform hits the economy unexpectedly at $t=5$.

The trajectory obtained for consumption confirms our earlier results from qualitative analysis. If the policy is anticipated, consumption falls already as soon as the reform becomes known indicating that households (shareholders) are eager to smooth consumption (wealth) and react to the expected lower taxes in the future by initiating an investment spurt today. The anticipation effect is quantitatively significant. If the tax reform comes unexpected, consumption stays at its initial level for the next 5 years and then falls by about twice as much as for the anticipated reform. In terms of current consumption (and thus instantaneous utility) ignorant households

12 An even larger effect of corporate taxes on firm finance than suggested by Gordon and Lee's estimate has recently been found by Djankov et al. (2008) in a cross-country study. They estimate that a 10 percentage point increase of the corporate tax rate raises the debt to equity ratio by 45 percentage points. 
are better off during the first five years and worse off afterwards when they have to adjust towards the new steady-state from a much lower level.

\section{Figure 3: Anticipated vs. Un-Anticipated Corporate Tax Reform}
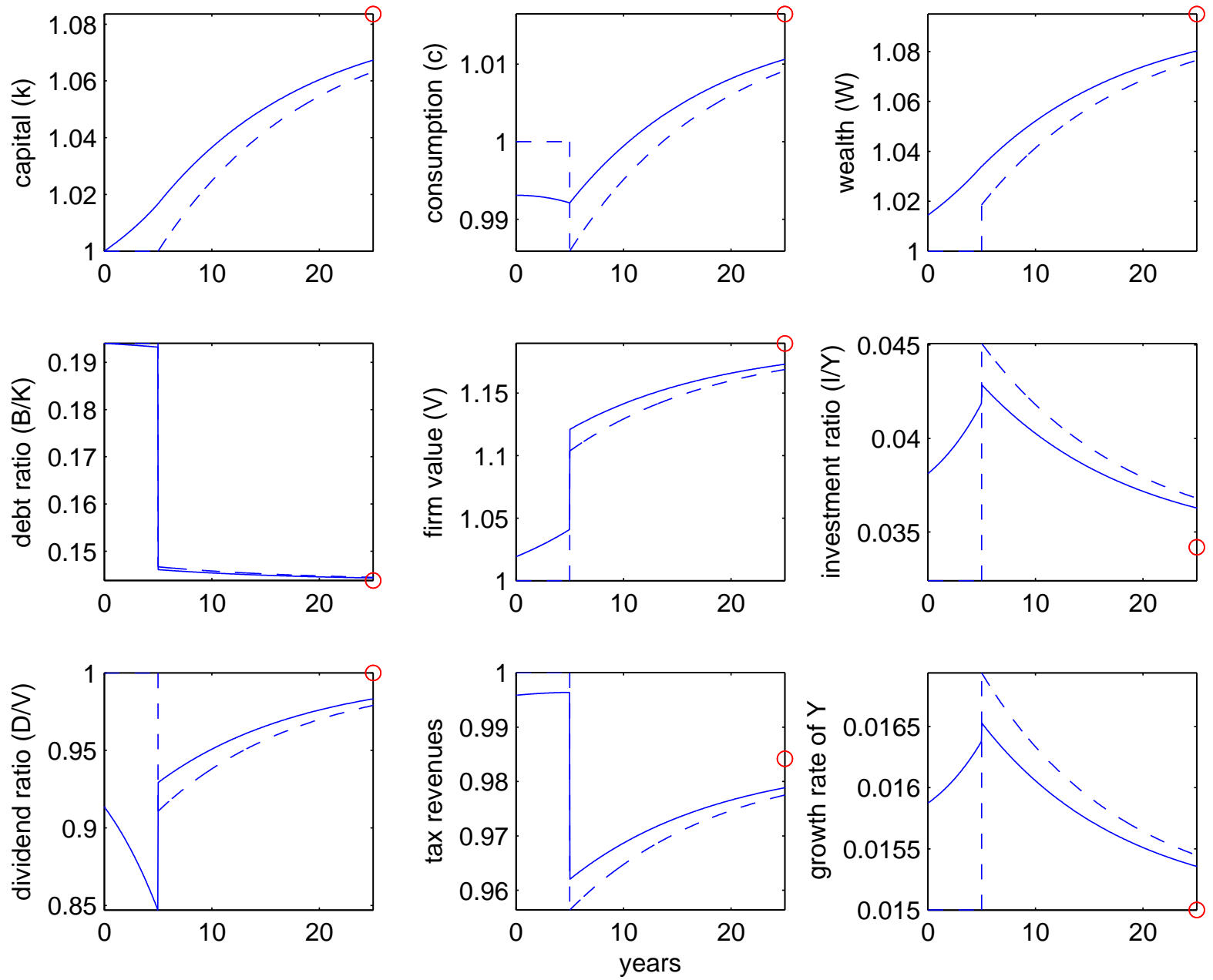

Adjustment paths for a 10 percentage point cut of the corporate tax rate that comes into effect in year 5. Solid lines: announcement at year 0. Dashed lines: unexpected reform. Macroeconomic aggregates measured in relative deviation from pre-reform steady-state; macroeconomic rates measured in percentage points.

As a consequence of anticipation the capital stock adjusts very smoothly. There is almost no kink visible at the time when the reform becomes operative. At the moment when the policy is enacted the capital stock is already about 2 percent above its pre-reform steady-state. This head-start advantage over the ignorant case is caught up only eventually when the economy reaches the new steady-state implying that pre-announcement of the reform makes firms bigger over the whole adjustment path. The finding of a size-effect from pre-announcement has been 
obtained previously in partial equilibrium (Summers, 1981) and is here confirmed in general equilibrium.

With contrast to real variables, adjustment behavior of financial structure is much more abruptly when the reform comes into effect and almost insensitive to pre-announcement. Firms react to the new tax law by replacing debt with equity thereby, as explained in Section 2, issuing new shares. This way the model can explain the occasional observation of new share issues. The model explains these issues as optimal reaction on tax reforms, which also happen only occasionally (or, generally, as optimal reaction to rare events that are exogenous to the single firm). Optimal financial policy is determined by capital stock and the tax system (and not by the shareholders' desire to smooth consumption). Thus the prior knowledge that a reform will happen has little effect. The only, almost invisible, movement of the debt ratio during the announcement phase is caused by the increasing capital stock.

The reduced tax advantage of debt implies that firms cut back temporarily dividends per share $(D / V)$ in order to finance above steady-state investment by retained earnings. The total value of shares, however, increases because of the increasing firm size. If the tax cut is pre-announced, share value increases already before the reform becomes operative. Larger firms pay absolutely more dividends such that dividends per share approach their initial value eventually.

As a consequence of increasing share value, households hold more shares and accumulate more wealth. Household wealth jumps at the moment when surprised firms adjust their financial structure by issuing new shares. For the pre-announced reform this happens immediately, at the moment of announcement. For the non-announced reform it happens at the moment of enactment. This implies that consumption falls for the pre-announced reform already during the announcement phase, indicating the incentive to save and invest already before the policy comes into effect.

The early investment spurt is also visible in the $I / Y$-panel. If the reform is anticipated, most of the total increase of investment happens already in the pre-reform phase with only a small jump when the reform comes into effect. It is beneficial for firms to accumulate capital stock in advance, which allows for high profits at the time when the tax on retained profits is reduced. If the reform comes unexpectedly, the jump of investment at reform time is much higher and it remains to be higher after the reform. Nevertheless, as inspection of the $k$ panel has made clear, 
the head-start advantage from pre-announcement with respect to capital stock (and profits) is only recovered as time goes to infinity.

Behavior of investment translates one-to-one into behavior of the growth rate of output per capita. Growth is predicted to be higher for an unanticipated reform. Again, this does not indicate at all a benefit from ignorance. Higher growth after enactment of the reform is insufficient to make up for growth during the anticipation phase when the reform comes expectedly.

The model predicts that the tax cut leads to an initial drop of government revenue of about 4 percent. Eventually, however, at the new steady-state the tax cut implies about 2 percent less revenue, indicating that about half of the policy is self-financing through induced higher investment and increasing economic activity. If the reform is anticipated, tax revenue falls already during the announcement phase because of lower revenue from dividend taxation. But the earlier expansion of the economy under an anticipated reform helps tax revenue to increase faster after the reform becomes operative.

In Figure 4 we present impulse responses for a pre-announced vs. unexpected increase of the investment tax credit by 20 percentage points. In many ways adjustment dynamics resemble those obtained for the corporate tax reduction albeit at smaller size, initially as well as eventually. Yet there are also qualitative differences between both reforms discernable.

To begin with, firms get more into debt when the higher tax credit comes into effect. This effect operates only temporarily in order to finance the higher investment triggered by the reform. While conventional wisdom would have probably predicted that investment will be delayed until the investment tax credit becomes operative, we observe, again, an investment spurt during the announcement phase.

This at first sight puzzling behavior is explained by costly debt. Firms anticipate that there will be large investments when the investment tax credit is granted. The entailed investment costs cannot be served spontaneously by retained earnings since profits are a flow variable. Issue of shares is also no option since the policy (with contrast to the corporate tax cut) leaves the financial structure desired in the long-run unaffected. Thus higher investment cost are expected to be served by higher debt. The implied higher leverage will increase the cost of debt. In order to mitigate the cost-effect from higher leverage, firms invest, i.e. accumulate capital, already in the announcement phase. During this period they pay less dividends and retain earnings in order to display a lower debt ratio $(B / K)$ when the reform comes into effect. 
Figure 4: Anticipated vs. Un-Anticipated Increase of Investment Tax Credit
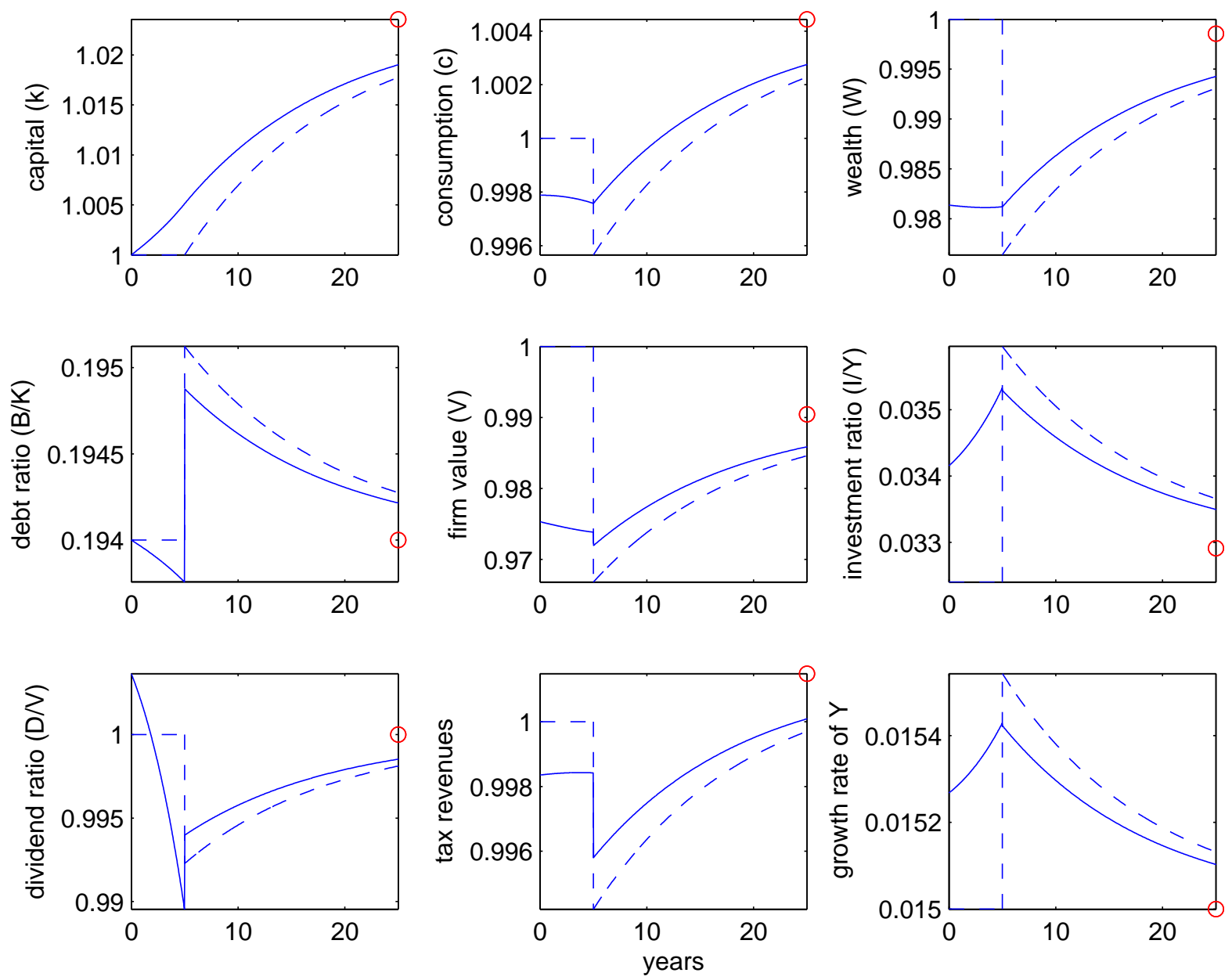

Adjustment dynamics after a 20 percentage point increase of $z$ that comes into effect in year 5 . Solid lines: announcement at year 0. Dashed lines: unexpected reform. Macroeconomic aggregates measured in relative deviation from pre-reform steady-state; macroeconomic rates measured in percentage points.

While the dividend ratio returns to its pre-reform value, total firm value is (with contrast to the corporate tax cut) predicted to be lower after the reform. Because long-run financial structure remains unchanged, permanently higher total investment has to be financed by both higher debt and higher equity. A higher stock of equity is accumulated through more retained earnings i.e. less dividends, which is reflected by a lower total value of firms (leaving the dividend ratio $D / V$ unchanged).

Interestingly, the model predicts for anticipated and unexpected reform diametrically opposed behavior of dividends when the reform comes into effect. If the reform arrives unexpectedly firms adjust by both higher debt and lower dividends in order to finance the higher investment needs. 
If the reform was anticipated, however, firms have already adjusted through lower dividends during the announcement phase and start to pay higher dividends (compared to last period, not compared to initial steady-state) when the reforms comes into effect.

Note also that the reform generates enough expansive power to become self-financing in the end and that it produces even a mild surplus of tax revenue. During transition, however, tax revenue is below its pre-reform value for a long time. If the reform was announced, tax revenue breaks even after about 20 years. As for other variables as well, adjustment dynamics for the unexpected reform lag behind, indicating, again, a genuine welfare gain from announcement.

In Figure 5 we consider an anticipated vs. unexpected reduction of the tax rate on private capital income (including dividends) by 10 percentage points at time $t=5$. Roughly speaking, results are less favorable than those obtained for the corporate tax reform. This is at first sight surprising since a reduction of $\tau_{p}$ is the only tax instrument that increases the net return on capital in the long-run. We can distinguish an interest rate channel inducing households to save more and a credit channel inducing households to hold a higher share of wealth in the form of bonds. Both effects are initiated simultaneously if the reform hits the economy unexpectedly. If the reform is anticipated, the credit channel operates mainly at the time when the reform comes into effect whereas the interest rate channel operates right from announcement onwards.

The head-start advantage from pre-announcement is again visible. When it becomes known that taxes on capital income will be lower in the future, households and firms immediately start to save and to invest. Again, early investment generates a size-effect from announcement that is only caught up as time goes to infinity if the reform hits the economy unexpectedly. During the announcement phase investment is mainly financed through retained earnings, i.e. lower dividends. When the reform comes into effect the tax advantage of debt increases and induces firms to raise their debt ratio and thus, in financial market equilibrium, induce households to hold a larger share of their wealth in bonds.

The model predicts for both pre-announced and unexpected reform that firm value and dividends decrease in the long-run. The loss of firm value is caused by a discount effect and a leverage effect. The discount effect originates from the fact that the cut of $\tau_{p}$ raises the interest rate $\left(1-\tau_{p}\right) r /\left(1-\tau_{c}\right)$ at which shareholders discount future dividends. It implies that firms are evaluated at a lower present value. The leverage effect originates from the fact that the tax cut 
Figure 5: Anticipated vs. Un-Anticipated Reform of Capital Income Tax
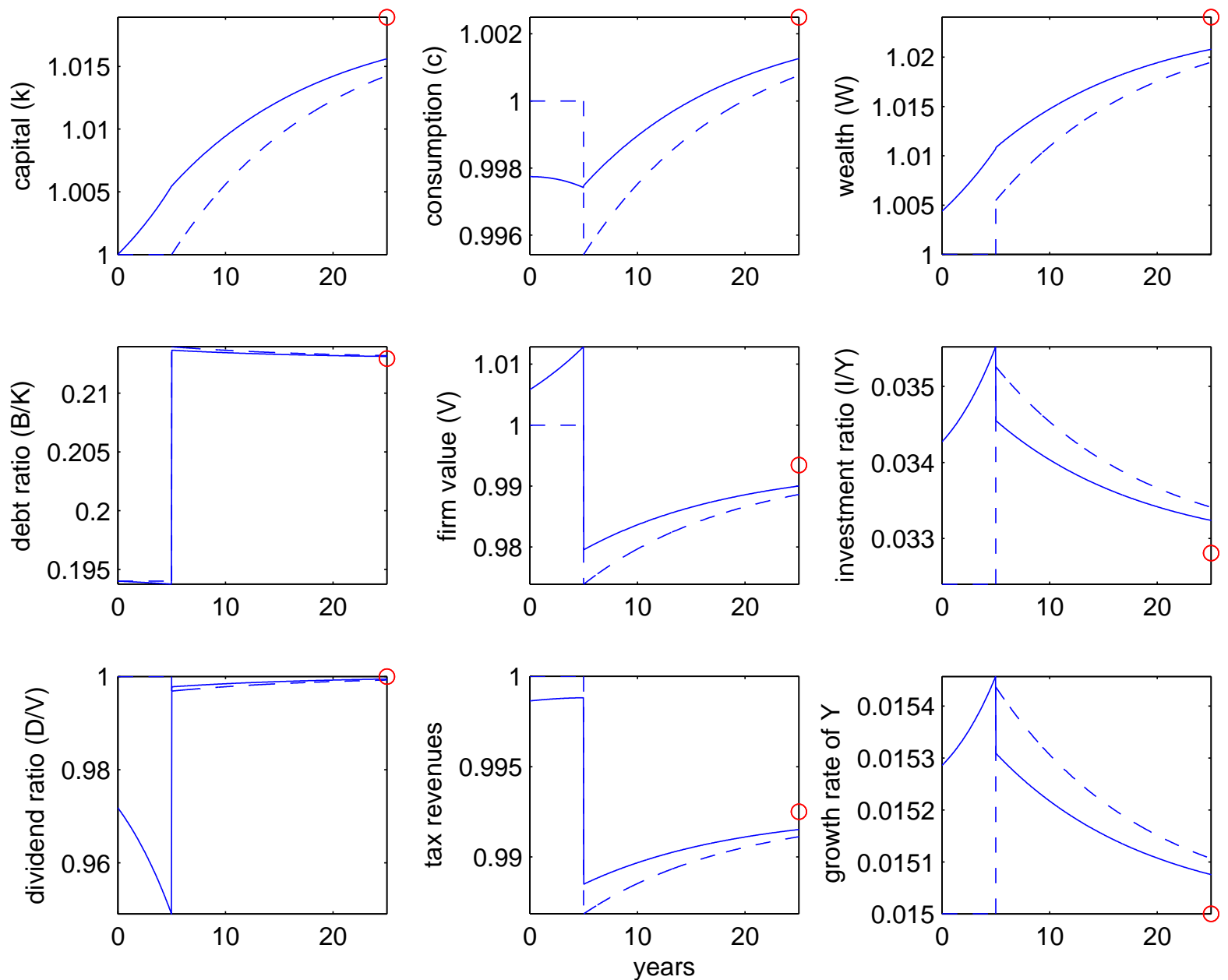

Adjustment Paths for a 10 percentage point reduction of $\tau_{p}$ comes into effect in year 5 . Solid lines: announcement at year 0. Dashed lines: unexpected reform. Macroeconomic aggregates measured in relative deviation from pre-reform steady-state; macroeconomic rates measured in percentage points.

induces a higher debt ratio and that the entailed higher costs of debt reduce the stream of dividends. In the long-run the dividend ratio $D / V$ converges towards its initial position indicating that dividends and firm value decrease by the same factor. Interestingly, the model predicts for the short run that firm value increases if the reform is pre-announced. This is because during the announcement phase, when firm size already expands, future dividends are still discounted with the pre-reform net interest rate. ${ }^{13}$

13 Note that the one time payment of a special dividend at $t=5$ is not visible in Figure 5 , which shows just the flow of regular dividends. According to (14) we compute a one time increase of dividends by $37 \%$ in the year when the reform becomes operative. Comparatively, the impact of the reform on special dividends is much larger than its impact on regular dividends. 
The most interesting differences between anticipated and unexpected reform are observed for investment and growth. Because much of the expansive power is already realized during the announcement phase if the reform comes anticipated, the model predicts in fact a small drop of the investment rate and the growth rate at the time when the lower tax rate becomes operative (compared to the previous period not compared to the pre-reform state). The opposite is true for an unexpected reform, which unfolds its highest momentum when it comes into effect. In that case the model predicts an increase of investment and economic growth at time $t=5$.

Next we evaluate the welfare consequences of tax reforms and, in particular, the extra welfare that can be generated through pre-announcement of a reform. ${ }^{14}$ For that purpose we employ the Lucas' (1990) methodology and measure the welfare gain of a tax reform as the constant relative increase in consumption that equates intertemporal utility from remaining in the state before the reform and switching towards the consumption path induced by the reform. Results are reported in Table 1. By way of example we also check for the robustness of results. It is well known that the shape of adjustment dynamics is most drastically affected by the choice for the elasticity of marginal utility $\sigma$ (see, for example, Barro and Sala-i-Martin, 2004). Our benchmark calibration has estimated $\sigma=2.6$. We report additionally results when $\sigma$ assumes values that are 33 percent higher and lower, respectively and where we have adjusted $\rho$ such that the model parameterization in any case implies a steady-state growth rate of 1.5 percent.

The column "welfare gain" in Table 1 shows the total welfare gain that can be expected from a certain policy reform. Similar exercises have been made in the related literature and, in particular, for the model at hand in Strulik (2003). The column "anticipation effect" shows the welfare gain that originates solely from the fact that a reform was pre-announced 5 years in advance. These genuinely new results are obtained by computing and comparing the welfare gains of an unexpected and an anticipated (non-marginal) tax reform. They allow us to assess how much welfare can expected to be generated from pre-announcement of a reform. For that purpose it may be helpful to recall that a one percent welfare gain (from abolishing capital taxation) has been appraised as the largest gain that quantitative welfare economics can provide (Lucas, 1990) and that the welfare gained by eliminating all business cycles has been estimated to be somewhere between 0.008 and 0.1 percent (Krusell and Smith, 1999).

\footnotetext{
${ }^{14}$ The result that a reduction of a distortionary tax is welfare-enhancing is, or course, not surprising. The interesting aspect here is how large a welfare can be expected and how much of the welfare gain originates from the fact that the reform was pre-announced.
} 
The first row in Table 1 shows that the total welfare gained from a 10 percentage point reduction of the corporate tax rate is estimated to be roughly one third of a percentage point. A welfare gain of 0.045 , roughly 10 percent of the total gain, originates from the fact that the reform was pre-announced and anticipated by households and firms. The welfare gain from pre-announcement appears to be small against the background of the large quantitative effects on macroeconomic aggregates just shown. The intuition here is that the extra utility gained along the higher consumption path after reform enactment (as compared to a surprising reform) is to a large degree counterbalanced by lower utility during the anticipation phase. Figuratively speaking, in the consumption panel of Figure 3, the large areas between solid and dashed line before and after enactment of the policy are of similar size. Then again, a welfare gain from anticipation of the reform of about 0.045 percent may equally well be assessed as quite large when compared to the gain from eliminating business cycles.

The size of the welfare gain is quite robust against alternative choices of $\sigma$. Not surprisingly, the lower $\sigma$ the higher the welfare gain from tax reform. Interestingly, this result takes over to the additional gain from anticipation. If $\sigma$ is smaller, the welfare gain from anticipation is somewhat higher as well. Summarizing we can conclude that anticipation of a corporate tax reform increases the welfare gain produced by the reform by roughly 10 percent.

Table 1: Welfare and Anticipation Effects of Tax Reforms

\begin{tabular}{l|ccc|ccc}
\hline \hline Policy reform & \multicolumn{3}{|c|}{ welfare gain } & \multicolumn{3}{c}{ anticipation effect } \\
\hline & $\sigma$ low & $\sigma$ benchmark & $\sigma$ high & $\sigma$ low & $\sigma$ benchmark & $\sigma$ high \\
$\Delta \tau_{r}=-0.1$ & 0.445 & 0.415 & 0.390 & 0.049 & 0.045 & 0.042 \\
$\Delta z=0.2$ & 0.106 & 0.097 & 0.090 & 0.016 & 0.015 & 0.015 \\
$\Delta z=0.1$ & 0.054 & 0.049 & 0.045 & 0.008 & 0.008 & 0.007 \\
$\Delta z=0.3$ & 0.208 & 0.190 & 0.175 & 0.032 & 0.030 & 0.029 \\
$\Delta \tau_{p}=-0.05$ & 0.003 & -0.004 & -0.009 & 0.016 & 0.017 & 0.017 \\
\hline$\Delta \tau_{p}=-0.05$ (Ramsey) & 0.169 & 0.155 & 0.144 & 0.025 & 0.024 & 0.023 \\
\hline \hline
\end{tabular}

Welfare gain measured in consumption equivalents and expressed in percent. See text for further explanations.

Next we report welfare consequences for an increase of the investment tax credit by 20 percentage points. Results are, in principle, similar to the case of corporate tax reduction. While the total welfare gain is smaller the extra gain from anticipation is, relatively speaking, somewhat larger and estimated to be about 15 percent of the total gain of the reform. Assuming lower and higher values of the tax credit we have checked for non-linear size effects, but found (almost) 
none within a reasonable range of $\Delta z$. As a rule of thump an $x$ percentage point increase of the tax credit generates an $0.5 x$ percentage point welfare gain.

Finally, we consider a 5 percentage point reduction of the tax rate on private capital income. Although the steady-state effect on consumption (and thus welfare) is mildly positive, taking adjustment dynamics into account the reform causes a mild welfare loss for the benchmark economy. The negative welfare consequences originate from financial restructuring and would, of course, not be present in the standard neoclassical growth model without endogenous corporate finance. Here, the tax advantage from lower $\tau_{p}$ induces firms to become more leveraged, which entails higher agency costs of debt, and reduces the claims of consumers on GDP. As a result, consumption exceeds its initial steady-state only after about 15 years. This time span is long enough such that the negative effect during the transitional period exceeds the positive impact on welfare at the steady-state. If the intertemporal elasticity of consumption gets larger ( $\sigma$ falls to by $1 / 3$ ), current consumption needs are less important and the reform produces a mild welfare gain. The isolated effect of anticipation is, of course, always positive. Again the gain from anticipation is, although absolutely small, relatively speaking quite large.

5.2. Temporary Tax Cuts. In this section we present the macroeconomic consequences predicted for temporary tax cuts. We begin with a temporary rise of the investment tax credit by 20 percentage points which is granted immediately and lasts for 5 years. Since the policy is temporary, the economy returns to its initial steady-state in the long-run. Despite its temporary character the policy may have positive consequences on welfare. For an intuition reconsider the right hand side panel of Figure 2. Consumption drops immediately and - following the logic explained in Section 3 - reaches the "old" manifold in year 5, i.e. when the tax relief expires. Along the manifold it travels from above towards the initial steady-state, which is reached as time goes to infinity. Since the manifold lies everywhere above the initial steady-state we can infer that consumption lies most of the time above its initial steady-state level $c^{*}$.

The results of our numerical computation, represented by solid lines in Figure 6, confirm this insight. Consumption drops initially in order to free resources for the additional investment triggered by the temporary tax cut. During the implementation phase (i.e. the period where the temporary policy is operative) consumption is on the rise again, breaks even with steady-state consumption after about 3 years and reaches its maximum at year 5 when the temporary tax 
cut terminates. It then adjusts slowly towards the initial steady-state. 20 years after the policy has terminated consumption is still (slightly) above steady-state level.

Figure 6: Temporary Increase of Investment Tax Credit
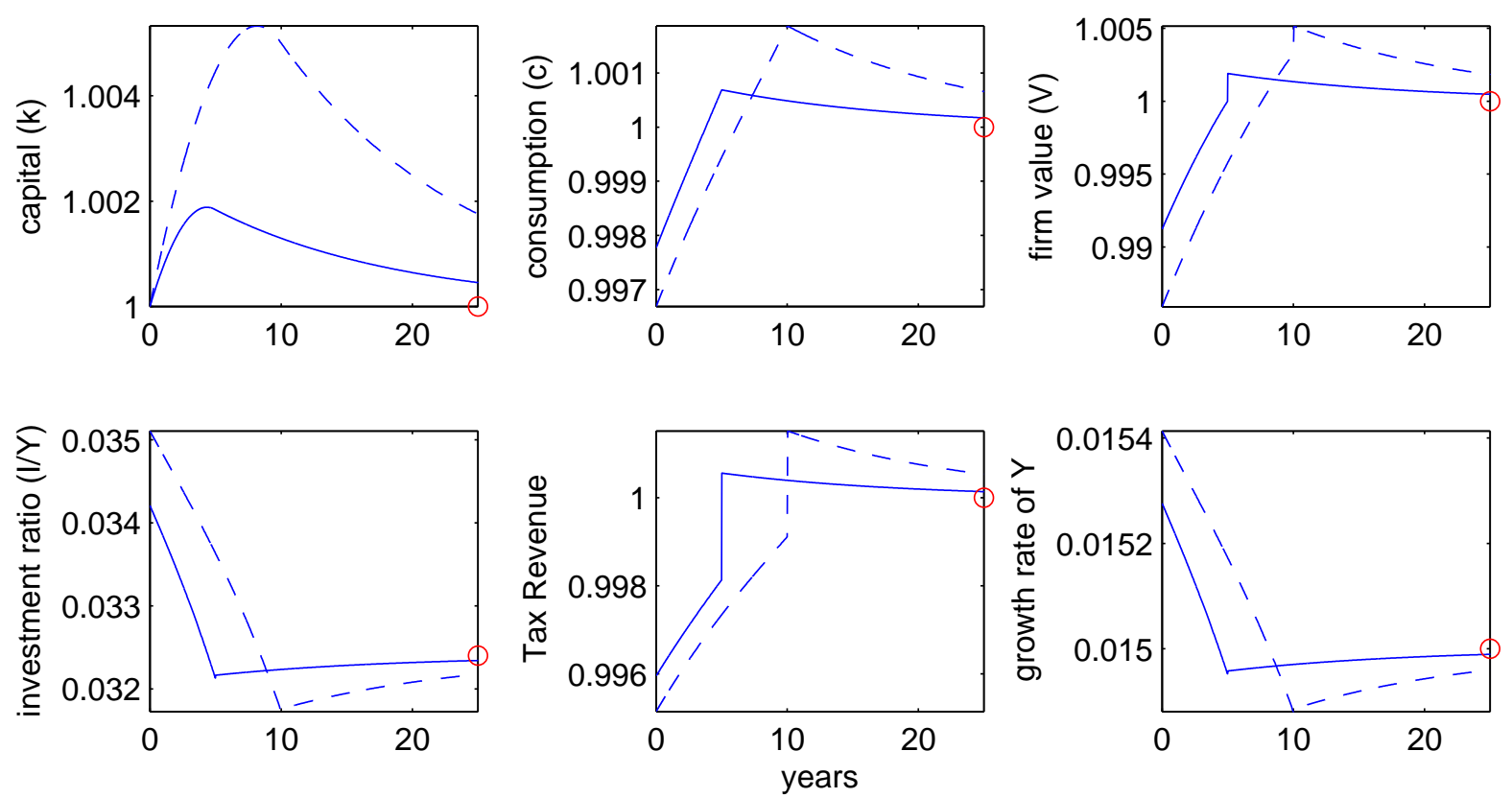

Adjustment Paths for a 10 percentage point increase of $z$ in year 0. Solid lines: policy is known to end in year 5. Dashed lines: policy is known to end in year 10. Macroeconomic aggregates measured in relative deviation from pre-reform steady-state; macroeconomic rates measured in percentage points.

To finance the additional investment firms have initially to recur on debt because retained earnings cannot jump. During the implementation phase firms finance the increased investment costs by paying less dividends and consequently firm value drops temporarily. Tax revenue, naturally, drops at the time when the larger tax credit is granted. It subsequently rises because profits and labor productivity rise, and lies above steady-state level after the tax cut expires because the "old" tax rates apply to temporarily higher capital stock, wages, and profits.

Dotted lines in Figure 6 show adjustment dynamics when the higher tax credit is granted for 10 years. Impulse responses are structurally similar but display, unsurprisingly, higher amplitudes. Capital stock is now accumulated for a longer period above steady-state level and consequently it takes longer until the positive effect vanishes after the policy has been terminated. Interestingly, the picture hints at a non-linearity. A doubling of the implementation phase from five to ten years leads to more than a doubling of the maximum amplitude, an effect that is in particular visible for capital stock and consumption. From this, one may infer that doubling the length 
Table 2: Welfare Effects of Temporary Tax Cuts

\begin{tabular}{l|ccc|ccc}
\hline \hline Policy reform & \multicolumn{3}{|c|}{5 years tax cut } & \multicolumn{3}{c}{ 10 years tax cut } \\
\hline & $\sigma$ low & $\sigma$ benchmark & $\sigma$ high & $\sigma$ low & $\sigma$ benchmark & $\sigma$ high \\
$\Delta z=0.2$ & 0.0069 & 0.0054 & 0.0044 & 0.0214 & 0.0176 & 0.0151 \\
$\Delta \tau_{r}=-0.1$ & 0.0554 & 0.0514 & 0.0489 & 0.1264 & 0.1157 & 0.1085 \\
\hline \hline
\end{tabular}

of the implementation period is more than twice as good for welfare, a hypothesis that we investigate next.

Table 2 shows the computed welfare gains and verifies that the temporary policy has indeed positive consequences on welfare. The welfare gain is, however, quite small compared to that of a permanent tax cut. If the extra tax credit is granted for 5 years, the model predicts a welfare gain of 0.0054 . The figures on the left show that if the policy is extended over a longer time the welfare gain rises indeed in a non-linear fashion. Doubling duration of the implementation phase produces a welfare gain of 0.0176 , i.e. it more than triples the welfare gain. Again, the result is quite robust against alternative specifications of parameters as exemplarily shown for alternative values of $\sigma$.

The next row in Table 2 shows that structurally similar results are obtained for a temporary cut of the corporate tax rate. Here, we have assumed that a 10 percentage point cut of $\tau_{r}$ is granted for five or ten years, respectively. Again, the policy arrives unexpectedly but agents know about its temporary character. The temporary tax relief spurs investment implying a temporary loss of consumption. As before, welfare raises because capital, output, and consumption overshoot their steady state values. Since the economy spends much longer time above its steady-state value than below, the gains in consumption outweigh the initial losses due to enhanced investment activities. A non-linearity with respect to duration is again visible albeit at a much smaller scale than for the investment tax credit. If the implementation period of the corporate tax cut doubles to ten years, the welfare gain is about 2.2 times higher.

Finally, we more systematically evaluate how much of the gain from a permanent reform can be produced by an otherwise identical temporary tax policy. In Table 3 we have compiled the welfare gain resulting from a 10 percentage point reduction of the corporate tax cut against the length of duration of the tax relief. In parenthesis we show how large this effect is in percent of the welfare gain produced by a permanent tax cut. For example, if the policy lasts indeed forever (as assumed in the first row), the welfare gain is 0.462 percent, which is, of course, 100 
Table 3: Welfare Effect of Temporary vs. Permanent Tax Relief

\begin{tabular}{l|ccc}
\hline \hline duration of tax relief & \multicolumn{3}{|c}{ welfare gain } \\
\hline & $\sigma$ low & $\sigma$ benchmark & $\sigma$ high \\
$\infty$ & $0.495(100 \%)$ & $0.462(100 \%)$ & $0.435(100 \%)$ \\
100 & $0.488(99 \%)$ & $0.455(99 \%)$ & $0.429(99 \%)$ \\
20 & $0.250(51 \%)$ & $0.230(50 \%)$ & $0.215(49 \%)$ \\
10 & $0.127(26 \%)$ & $0.116(25 \%)$ & $0.109(25 \%)$ \\
5 & $0.055(11 \%)$ & $0.051(11 \%)$ & $0.0049(11 \%)$ \\
\hline \hline
\end{tabular}

Policy: corporate tax cut of 10 percentage points. In parenthesis: total welfare gain compared to the one resulting from an everlasting tax relief.

percent of the permanent effect. As a robustness check for our results we calculate again the welfare gain for the same policy change when $\sigma$ is 33 percent lower or higher than assumed for the benchmark model.

For an assessment note that Table 3 assumes that policies come into effect immediately. A comparison with results from Table 1 reveals that the welfare gain from having the permanent reform immediately is higher than the welfare gain from having the same reform in 5 years from now taking into account the extra welfare gained from announcement. In other words, the fact that announcing a reform in advance is always welfare enhancing ceteris paribus, i.e. holding the date of enactment constant, does not imply that a generally favorable reform should be "artificially" delayed in order to realize this extra gain from announcement.

As expected, if the tax relief lasts for 100 years, the deviation of welfare from the one obtained for a permanent change is very small. If the tax relief is granted for 20 years the deviation is already significant. The welfare gain is 0.23 percent, which is roughly half the gain obtained for the permanent policy. A ten year tax relief yields just about 25 percent of the welfare gain of the respective permanent policy. For a 5 year tax cut the welfare gain melts down to a mere 11 percent. Results are again quite robust against parameter variation.

Welfare gains from permanent tax policy changes have been analyzed by several numerical studies in the past. The question may have been occurred whether the findings could be used to assess the welfare gain resulting from an actual policy change that is known to be nonpermanent. This would be very convenient since welfare consequences of permanent policy changes are much easier to compute (which may be actually one reason for why they are more prevalent in the literature). The results compiled in Table 3, however, indicate that we would 
accept large errors if we treated a temporary tax relief as if being permanent. The error made is, naturally, decreasing in the actual duration of the tax relief.

With Figure 7 we explore the underlying adjustment dynamics. The figure shows the optimal consumption path triggered by a tax relief of different duration. The individual paths are easily identified since we know from phase diagram analysis that consumption peaks when the policy is terminated. The path that peaks at $t=5$ thus reflect the consumption trajectory provoked by a 5 year tax relief. The path that peaks "outside of the figure" reflects the 100 year policy, and the dashed line shows steady-state consumption that would be eventually assumed if the tax cut were indeed permanent. The solid horizontal line shows consumption at the old steady-state, i.e. without any tax relief. All numbers are measured relative to initial consumption. Remaining at the initial steady-state thus yields one unit consumption at each period of time forever.

\section{Figure 7: Temporary Tax Cuts and Optimal Consumption Paths}

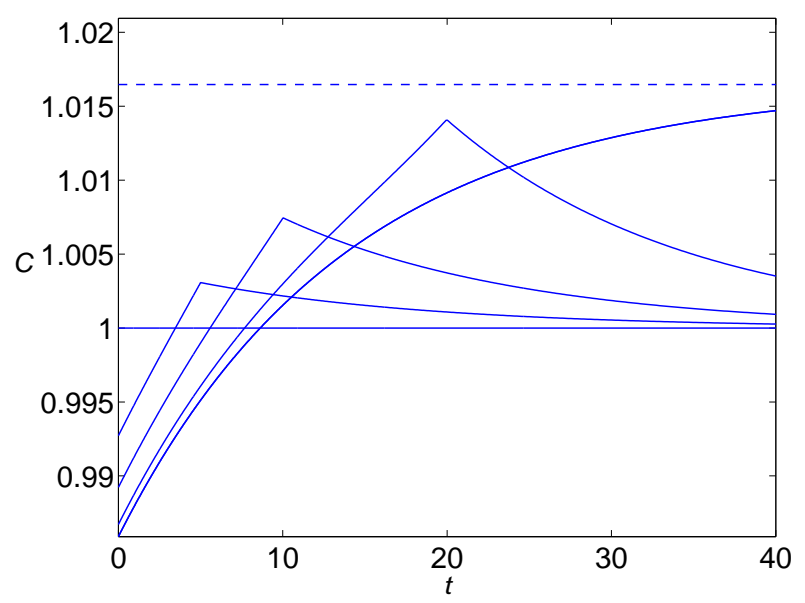

Policy: corporate tax cut of 10 percentage points. The curves show consumption optimal paths for alternative duration of the policy. Each curve peaks when the temporary tax relief expires, i.e. after 5, 10, 20, 100 years.

While the initial drop of consumption is of comparable magnitude for all policies, the most striking result visible in Figure 7 is how small the maximum yield of consumption gets when the duration of the tax relief is shortened. The comparatively small welfare gain computed for a temporary tax relief of 5 or 10 years thus originates chiefly from the fact that consumption never - not even for a short time - comes close to the consumption yield that a permanent policy eventually produces. The Figure impressively documents the supply-side mechanism. In the end, everything is driven by supply of capital (or, more generally, factor accumulation). A tax cut of short duration leads to a short spurt of investment activities and a small (and, of course, 
only temporary) increase of factor endowments. Consequently, it can support only a short and small increase of consumption and welfare. In conclusion, even if a tax cut is quite drastic, it is ill-judged to expect large positive consequences on welfare when the relief is simultaneously of short duration, for example, if it is operative for "only" one legislative period.

\section{Conclusion}

In this paper we have applied a new method to evaluate the quantitative macroeconomic consequences of anticipated tax reforms and temporary tax cuts. The mechanics of the numerical algorithm can be retraced by phase diagram analysis, a fact that facilitates an intuitive explanation of the obtained impulse response behavior.

We have found that adjustment dynamics for anticipated policy reform differs significantly from an unexpected reform. In particular, we have demonstrated that a pre-announced cut of taxes causes a sizeable investment spurt during the announcement phase, i.e. before the reform becomes operative. The investment spurt generates a head-start advantage of the announced reform vis a vis a surprising (but otherwise identical) reform, which is only caught up as time goes to infinity. For a reduction of corporate taxes we predict that a five year lead of preannouncement generates an extra welfare gain of about 10 percent of the total gain from the reform, which is estimated to be more than a third of a percentage point for a ten percentage point tax cut. A structurally similar investment spurt and extra welfare gain arises from preannouncement of a higher future investment tax credit. Results are less favorable for taxation of private capital income. The again positive announcement effect is not sufficient to turn a (mildly) negative welfare effect positive.

Besides these quantitative results we have also found and explained important qualitative differences between pre-announced and surprising tax reforms. These differentiated effects are caused by adjustment of financial structure, which is modeled as endogenous in our setup. For example, dividends are predicted to rise when a pre-announced investment tax credit becomes operative but are predicted to fall in case of a surprising policy. For a cut of private capital income taxes the model predicts that the investment rate falls (vis a vis the previous period) when an announced tax cut comes into action while it is predicted to rise in case of a surprising tax cut. With respect to actual policy evaluation these findings suggest that one has to sort out 
carefully whether a reform came expectedly or surprisingly, in particular, for the interpretation of events around the time when a reform becomes operative.

Finally, we were able to demonstrate a genuine welfare gain arising from a temporary cut of the corporate tax rate and from a temporarily higher investment tax credit. While small initially the gain rises with length of the implementation period. In particular for the investment credit we have found a non-linearity. Doubling the implementation period more than triples the welfare gained. We have demonstrated that temporary policy in general drastically under-performs vis a vis a permanent policy, in particular when the implementation period is short. For example, if the corporate tax cut is granted for five years it generates around 11 percent of the welfare obtained from a permanent tax cut of equal size. This implies that large errors are excepted when a tax policy which is known to be temporary is evaluated as if being permanent.

We have generally found that there is much more variation in impulse responses of important macroeconomic variables than indicated by the aggregated welfare gain. The aggregation over time hides the fact that ups and down of investment, profits and consumption before and after reform are to a large extent counterbalancing each other. We thus expect important intergenerational distribution effects from the anticipation of future policies. An extension of our method towards a Blanchard (1985) - Yaari (1965) setup seems to be a promising project for the future.

Acknowledgements. We would like to thank Volker Grossmann and two anonymous referees for very useful comments on an earlier draft. 


\section{References}

Abel, A., 1982, Dynamic effects of permanent and temporary tax policies in a $q$ model of investment, Journal of Monetary Economics 9, 353-373.

Alvarez, L., V. Kanniainen, and J. Soedersten, 1998, Tax policy uncertainty and corporate investment: A theory of tax-induced investment spurts, Journal of Public Economics 69, $17-48$.

Auerbach, A.J., 1989, Tax reform and adjustment costs: The impact on investment and market value, International Economic Review 30, 939-962.

Auerbach, A., 2001, Taxation and corporate financial policy, NBER Working Paper 8203.

Barro, R.J., and X. Sala-i-Martin (2004) Economic Growth, MIT Press, Cambridge, MA.

Baxter, M. and R.G. King, 1993, Fiscal policy in general equilibrium, American Economic Review 83, 315-334.

Blanchard, O., 1985, Debt, deficits, and finite horizons, Journal of Political Economy 93, 223247.

Brunner, M. and H. Strulik, 2002, Solution of perfect foresight saddlepoint problems: A simple method and applications, Journal of Economic Dynamics and Control 26, 737-753.

Carey, D., and H. Tchilinguirian, 2000, Average effective tax rates on capital, labour, and consumption, OECD Working Paper No. 258

Cooley, Th.F. and G. D. Hansen, 1992, Tax distortions in a neoclassical monetary economy, Journal of Economic Theory 58, 290-316.

Djankov, S., Ganser, T., McLeish, C., Ramalho, R., and Shleifer, A., 2008, The effect of corporate taxes on investment and entrepreneurship, NBER Working Paper 13756.

Domeiij, D. and P. Klein, 2005, Preannounced optimal tax reform, Macroeconomic Dynamics 9, 150-169.

Gordon, R.H and Y. Lee, 2001, Do taxes affect corporate debt policy ? Evidence form U.S. corporate tax return data, Journal of Public Economics 82, 195-224.

Gordon, R.H and Y. Lee, 2007, Interest rates, taxes and corporate financial policies, National Tax Journal, 65-84.

Graham, J.R., 2000, How big are the tax benefits of debt?, Journal of Finance 55(5), 1901-1941.

Graham, J. R., 2006, Taxes and corporate finance, in: B. E. Eckbo (ed.): Handbook of Corporate Finance - Empirical Corporate Finance, Amsterdam: Elsevier Science.

Greenwood, J. and G.W. Huffman, 1991, Tax analysis in a real business cycle model, Journal of Monetary Economics 27, 167-190.

Grüner, H.P. and B. Heer, 2000, Optimal flat-rate taxes on capital - A re-examination of Lucas' supply side Model, Oxford Economic Papers 52, 289-305. 
Gourio, F. and J. Miao, 2010, Firm Heterogeneity and the long-run effects of dividend tax reform, American Economic Journal: Macroeconomics 2, 131-168

Howitt, P. and H.-W. Sinn, 1989, Gradual reforms of capital income taxation, American Economic Review 79, 106-124.

Judd, K.L., 1987, Welfare cost of factor taxation in a perfect foresight model, Journal of Political Economy 95, 298-319.

Judd, K.L., 1985, Short-run analysis of fiscal policy in a simple perfect foresight model, Journal of Political Economy 95, 298-319.

Kim, S.-J., 1998, Growth effect of taxes in an endogenous growth model: To what extent do taxes affect economic growth?, Journal of Economic Dynamics and Control 23, 125-158.

King, R.G., and S. Rebelo, 1990, Public policy and economic growth: Developing neoclassical implications, Journal of Political Economy 98, S126-S151.

Krusell, P., and Smith, A.A., 1999, On the welfare effects of eliminating business cycles, Review of Economic Dynamics 2, 245-272.

Laitner, J., 1995, Quantitative evaluations of efficient tax policies for Lucas' supply side models, Oxford Economic Papers 47, 471-492.

Li, Y.T., and R. Wong, 2008, Integral and series representations of the Dirac delta function, Communications on Pure and Applied Analysis 7, 229-247.

Lucas, R.E., Jr., 1990, Supply-side economics: An analytical review, Oxford Economic Papers 42, 293-316.

McGrattan, E.R., 1994, The macroeconomic effects of distortionary taxation, Journal of Monetary Economics 33, 573-604.

McGrattan, E.R., and E.C. Prescott, 2005, Taxes, regulations, and the value of U.S. and U.K. corporations, Review of Economic Studies 72, 767-796.

Mendoza, E.G., G.M. Milesi-Ferretti, and P. Asea, 1997, On the ineffectiveness of tax policy in altering long-run growth: Harbergers's superneutrality conjecture, Journal of Public Economics 66, 99-126.

Mendoza, E.G., and L.L. Tesar, 1998, The international ramifications of tax reforms: supplyside economics in a global economy, American Economic Review 88, 226-245.

Mountford, A. and H. Uhlig, 2008, What are the effects of fiscal policy shocks?,NBER Working Paper 14551.

OECD, 1991, Taxing Profits in a Global Economy: Domestic and International Issues, OECD, Paris.

Osterberg, W.P., 1989, Tobin's $q$, investment, and the endogenous adjustment of financial structure, Journal of Public Economics 40, 293-318. 
Poterba, J.M., 2004, Taxation and corporate payout policy, American Economic Review, Papers and Proceedings 94, 171-175.

Romer, C.D. and D.H. Romer, 2008, The macroeconomic effects of tax changes: estimates based on a new measure of fiscal shocks, Working Paper, Berkely.

Sinn, H.W., 1987, Capital income taxation and resource allocation, North-Holland, Amsterdam.

Stokey, N.L., Rebelo, S., 1995, Growth effects of flat-rate taxes, Journal of Political Economy $103,519-550$.

Strulik, H., 2003, Capital tax reform, corporate finance, and economic growth and welfare, Journal of Economic Dynamics and Control 28, 595-615.

Strulik, H., 2008, The credit channel of capital tax policy, Journal of Public Economic Theory forthcoming.

Summers, L.H., 1981, Taxation and corporate investment: A $q$-theory approach, Brookings Papers on Economic Activity 1:1981, 67-127.

Trabandt, M. 2007, Optimal pre-announced tax reform revisited, Economic Working Papers ECO2007/52, European University Institute.

Trimborn, T., K.-J. Koch, and T.M. Steger, 2008, Multi-dimensional transitional dynamics: A simple numerical procedure, Macroeconomic Dynamics, 12, 1-19.

Turnovsky, S.J., 1982, The incidence of taxes: A dynamic macroeconomic analysis, Journal of Public Economics 18, 161-194.

Turnovsky, S.J., 1990, The effects of taxes and dividend policy on capital accumulation and macroeconomic behavior, Journal of Economic Dynamics and Control 14, 491-521.

Yaari, M.E., 1965, Uncertain life-time, life insurance, and the theory of the consumer, Review of Economic Studies 32, 137-150. 